many more opportunities for lateral movement within government service that would be expected to carry scientists outside the narrow practice of research and development into administration and management. This is not merely a way of saving the careers of technical people in government service but also a source of the technical skills which the rest of the Civil Service needs. It is a great misfortune that so little has been done in the years since the Fulton commission reported to put flesh on this skeleton. It is another misfortune that the CBI committee has made too little of those opportunities.

\title{
Taxation and Women's Liberation
}

Mr ANTHONY BARBER, the Chancelior of the Exchequer in Mr Heath's new British government, is unlikely to be mistaken for a social radical of the kind likely to be found marching with the Women's Liberation through the streets of London. It is therefore a little ironical that, in his Budget last week, he should have taken one of the most significant steps for several years towards meeting the demands of those who consider that women are at present unfairly treated in British society and that something should be done to redress the balance. Last Tuesday, Mr Barber announced that from April 1972, women who work will not have to suffer the indignity of having their earnings aggregated with those of their husbands for taxation purposes. Gone in one step will be the old British joke that cohabitation without marriage is an effective means of income tax avoidance. The interesting question, for women in the Women's Liberation movement as well as for their husbands, is whether Mr Barber's innovation will make much difference to the frequency with which married women at present go to work and to the way in which they are regarded when they get there.

Although $\mathrm{Mr}$ Barber's incentives are likely to carry weight with many women, it is unlikely that they will satisfy the Women's Liberation or, more important, substantially improve the chances that women will find it possible to go out to work in greater numbers. As any aspiring Kate Millett will find out, there are practical as well as financial obstacles to be overcome. The most obvious is that women who wish to combine careers and children often find it necessary to put the children first. It is not merely a question of having to stay at home for measles. Much more important is the now well demonstrated truth that young children up to four or five need more of some parent's attention than the full blooded pursuit of a profession will allow. The Women's Liberation is probably right in asking that there should be better facilities for caring for children during the day (and Mr Barber's Budget may make this easier by simplifying payment for day nurseries) but that is only a small part of the battle. The most serious difficulty is that no amount of enlightened public administration will help to banish the awkward fact that working women are likely for a long time to be more severely handicapped than their husbands by the need to care for children. The question is not whether to ignore this awkward truth but how to make its influence less obviously a source of social injustice towards women.

What is to be done? If the Women's Liberation movement were prepared to take a level-headed view of its responsibilities, it would first of all concentrate on demonstrating that responsibility for child care is not nearly as serious a handicap as employers frequently pretend. To be sure, there are inevitable risks in taking, say, five years off in the middle of a career as a ballet dancer or a pianist. With most kinds of intellectual work, however, the damage done by interruption is not nearly as important. Moreover, it can often be arranged that women carry on with part-time work while looking after children. Over a period of years, women must often be more diligent and more constant employees than men, who more often flit from place to place in pursuit of their careers. In all the circumstances, what the Women's Liberation should and could now undertake is to exploit the potential benefits of Mr Barber's concession by a shrewd demonstration of the potential advantages of working women. Such an undertaking would be important not merely for the women concerned but for all who are alarmed at the waste of talent unemployed.

\section{Yeurs Aun}

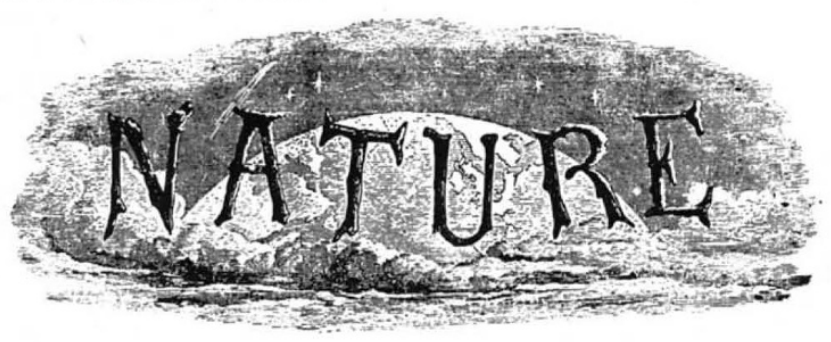

The principal reason why there has been greater scope for the improvenmt of the steam engine than for the electro-magnetic engine arises from the circumstance that in the formula $\frac{a-b}{a}$, applied to the steam engine by Thomson, in which $a$ and $b$ are the highest and lowest temperatures, these values are limited by practical difficulties. For $a$ cannot easily be taken above $459^{\circ}+374^{\circ}$ $=833^{\circ}$ from absolute zero, since that temperature gives 12.425 atmospheres of pressure, nor can $b$ be readily taken at less than the atmospheric temperature or $449^{\circ}$ $+60^{\circ}=519^{\circ}$. Also there is much difficulty in preventing the escape of heat; whereas the insulation of electricity presents no difficulty,

I had arrived at the theory of the electro-magnetic engine in 1840, in which year I published a paper in the 4th Vol. of Sturgeon's Annals, demonstrating that there is "no variation in economy, whatever the arrangement of the conducting metal, or whatever the size of the battery." The experiments of that paper indicate $36 \mathrm{ft}$. lbs. as the maximum duty for a grain of zinc in a Wollaston battery. Multiplying this by 4 to bring it to the intensity of a Daniell's battery, we obtain I 44 foot lbs. Here, as in the experiments in the paper on Mechanical Powers of Electro. Magnetism, Steam, and Horses, the actual duty is less than the theoretic; which is owing partly to the pulsatory nature of the current, and partly also to induced currents giving out heat in the substance of the iron cores of the electro-magnets; although these last were obviated as far as possible by using annealed tubes with slits down their sides. J. P. JOULE

From Nature, 3, 475, April 13, 1871 